\title{
A LibertaÇão dos EgípCios (Ex 3, 22; 12, 36)
}

\author{
THE LIBERATION OF EGYPTIANS (EX 3, 22; 12, 36)
}

\author{
Matthias Grenzer* \\ Patricia Carneiro de Paula**
}

\begin{abstract}
RESUMO
A macronarrativa sobre o êxodo nos últimos quatro livros do Pentateuco, literatura que origina todas as teologias políticas de cunho judaico-cristão, não conta apenas como os hebreus foram libertados da servidão no Egito. Ao contrário, de forma expressa e surpreendente, os textos também insistem, por duas vezes, na libertação dos egípcios, dinâmica inicialmente realizada a partir de um diálogo entre mulheres hebreias e egípcias. Em vista de uma maior clareza desse detalhe, o artigo aqui apresentado investiga parte das formulações em Ex 3, 22; 12, 36, sendo que as duas palavras hebraicas em questão - ver a raiz verbal traduzida aqui como libertar e o substantivo traduzido como egípcios - se tornam o objeto de estudo nesta pesquisa. De acordo com a metodologia comumente proposta pela exegese moderna, valorizam-se estudos linguístico-literários e histórico-teológicos pormenorizados das formulações bíblicas, sendo que todas as investigações partem da análise do texto originalmente composto em hebraico. Como resultado, será possível descobrir detalhes que, no que se refere à complexidade e à abrangência do projeto do êxodo, permitem uma compreensão mais exata e, portanto, melhor do que a narrativa bíblica, como literatura religiosa, propõe a seu ouvinte-leitor.
\end{abstract}

Palavras-chave: Literatura bíblica. Pentateuco. Êxodo. Egito. Libertação.

\begin{abstract}
The macronarrative about the Exodus in the last four books of the Pentateuch, literature that originates all Jewish-Christian political theologies, does not just tell how the Hebrews were freed from bondage in Egypt. On the contrary, in an express and surprising way, the texts also insist, twice, on the liberation of the Egyptians, a dynamic carried out through a dialogue between Hebrew and Egyptian women. For the sake of clarity of this detail, the article presented here investigates part of the formulations in Ex 3: 22; 12: 36, and the two Hebrew words in question seeing the verbal root translated here as liberate and the noun translated as Egyptians - become the object of study in this research. According to the methodology commonly proposed by modern exegesis, detailed linguistic-literary and historical-theological studies of biblical formulations are valued, and all investigations start from the analysis of the text originally composed in Hebrew. As a result, it will be possible to discover details that, with regard to the complexity and scope of the exodus project, allow for a more accurate and thus better understanding of what the biblical narrative, as religious literature, proposes to its reader-listener.
\end{abstract}

Keywords: Biblical Literature. Pentateuch. Exodus. Egypt. Liberation.

\footnotetext{
* Doutor em Teologia pela Faculdade de Filosofia e Teologia St. Georgen em Frankfurt, Alemanha, e mestre em História pela PUC-SP. É professor na Faculdade de Teologia da PUC-SP e líder do Grupo de Pesquisa TIAT - Tradução e Interpretação do Antigo Testamento. ORCID no oooo-0003-3490-3112. E-mail: mgrenzer@pucsp.br.

${ }^{* *}$ Mestranda em Teologia. Bacharel em Direito e Teologia. Membra do Grupo de Pesquisa TIAT. ORCID ${ }^{\circ}$ oooo-0002-4555-1362. E-mail: patriciacdepaula@terra.com.br.
} 


\section{INTRODUÇÃO}

A macronarrativa do êxodo, nos últimos quatro livros do Pentateuco (Ex-Dt), apresenta um enredo no qual o Senhor, Deus de Israel, liberta o povo dos hebreus “[...] da mão dos egípcios e/ou da mão do faraó” (Ex 3, 8; 18, 10). Nesse sentido, o Senhor é descrito como quem "faz o bem a Israel” (Ex 18, 9), uma vez que “[...] o faz sair de debaixo das cargas dos egípcios [... a fim de] libertá-lo de sua servidão” (Ex 6, 6). Isso, por sua vez, inclui a necessidade de “[...] o Senhor, por causa de Israel, agir com o faraó e com os egípcios” (Ex 18, 8), em razão de se opor firmemente ao poder opressivo.

Percebe-se, assim, que a narrativa bíblica, à primeira vista, assume uma perspectiva social e política que visa a dois grupos antagonistas: de um lado, quem ocupa o papel de opressor - no caso, o faraó e os egípcios -, e, do outro, o oprimido e necessitado de libertação. Embora a narrativa sobre o êxodo cultive a ideia de que, junto aos hebreus, tenha saído do Egito uma “[...] numerosa mescla de gente” (Ex 12, 38) - evitando-se pensar o projeto do êxodo como projeto nacional! -, cabe aos filhos de Israel a tarefa de representar o oprimido, que, em meio à sua miséria, tem o destino invertido, evidenciando-se, portanto, uma consciência crítica a respeito das consequências da opressão sofrida.

Contudo, uma escuta ou leitura mais atenta descobrirá que o livro do Êxodo, aparentemente, propõe a seus ouvintes-leitores também uma reflexão mais complexa e pormenorizada sobre os(as) egípcios(as) e/ou o Egito como nação (Ex 9, 24), o que, em seguida, vale semelhantemente para a reflexão sobre as demais etnias não israelitas. Ou seja, os textos bíblicos em questão parecem diferenciar egípcio de egípcio e, desse modo, sublinhar a experiência de que, assim como entre o povo israelita, também no Egito havia pessoas e grupos populacionais com pensamentos e comportamentos diferentes; algo que, por sua vez, lhes provocaria também destinos diferentes.

A título de introdução, todas as citações bíblicas neste estudo são tradução própria, tendo como fonte a edição crítica da Biblia Hebraica Stuttgartensia (ELLIGER; RUDOLPH, 1997). As siglas dos livros bíblicos seguem o que se define na Bíblia de Jerusalém (2002, p. 15-16).

\section{O EGITO NO LIVRO DO ÊXODO}

Nenhum outro livro na Bíblia Hebraica menciona mais vezes o Egito e os(as) egípcios(as) do que o livro do Êxodo. Como nome de nação e/ou país, o substantivo Egito (מִצִרי!ם) ocorre cento e setenta e cinco vezes no segundo livro do Pentateuco. Como gentílico, 
forma que indica pertença de alguém a um povo ou a uma tribo, o substantivo e/ou adjetivo

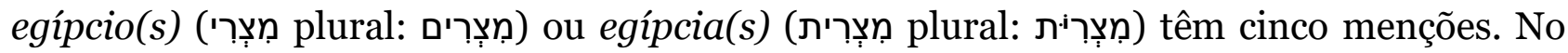
caso do plural masculino, por sua vez, somente o texto massorético - trabalho hermenêutico medieval para facilitar a leitura pelo acréscimo de sinais vocálicos no texto hebraico mais antigo, escrito somente com consoantes - permite a distinção entre Egito (מְִִִרִים) e egípcios (מִצִרים), uma vez que as consoantes são as mesmas. Na Bíblia Hebraica, portanto, um quarto de todas as menções do povo no vale do rio Nilo se encontra no livro do Êxodo.

Em todos os períodos de sua existência, o antigo Israel refletiu sobre o Egito, sendo que a grandeza política, econômica e cultural da nação vizinha no sudoeste originou discursos diferentes. De um lado, os Profetas, que atuaram e escreveram no decorrer do primeiro milênio a.C., contemplam o Egito em vista da relevância dele para a política externa de Israel e Judá. Do outro, os Escritos Sapienciais, ao olharem para o Egito, visam à sabedoria e às diferenças culturais do povo vizinho. Focando, por sua vez, no que é narrado no Pentateuco e, em especial, no livro do Êxodo, prevalece amplamente um discurso teológico-libertador, no sentido de o Senhor, Deus de Israel, ser meditado e confessado como quem inverte o destino daqueles que sofrem com o Egito, uma vez que o poder faraônico nas terras do rio Nilo insiste em políticas opressivas (KESSLER, 2002).

Não obstante isso, ao controlar o total das cento e oitenta presenças do Egito no segundo livro do Pentateuco, percebe-se uma reflexão mais ampla e diferenciada sobre essa nação e sobre seu povo do que talvez se imagine em um primeiro momento. De forma alguma as narrativas sobre o evento do êxodo limitam o Egito a algo exclusivamente negativo, que, de forma antagônica, somente contrastaria Israel e/ou o povo hebreu. Eis alguns exemplos para ilustrar o que aqui é afirmado.

Logo no início, o livro do Êxodo cultiva a memória de como os filhos de Israel, a partir dos setenta descendentes de Jacó, se transformaram, justamente no Egito, em um povo numeroso (Ex 1, 1-7). Lembra-se com isso do que é narrado no livro do Gênesis, texto que antecede o livro do Êxodo:

No que se refere às histórias dos patriarcas e matriarcas, somente Isaac e Rebeca não passaram pelo Egito, sendo que as secas repetidas na região de Canaã eram a causa de tais migrações (Gn 26, 1-2). As terras no vale do Nilo, pois, não dependem da água proveniente da chuva, porque podem ser irrigadas com a água do rio. Na região de Canaã, por sua vez, a ausência da chuva significa seca e fome, um problema a ser enfrentado de geração em geração. Abraão e Sara foram os primeiros a descerem ao Egito (Gn 12, 10-20). Mais tarde, Jacó enviou dez dos onze irmãos de José ao vale do rio Nilo, a fim de comprarem grãos quando a terra inteira ia ao Egito em razão da forte fome $(\mathrm{Gn} 41,57 ; 52,3)$. Tal movimento se repetiu quando, ao se prolongar a fome, os onze irmãos de José foram enviados, outra vez, pelo pai, Jacó (Gn 43, 1-2). Mas desta vez José, que tinha sido vendido por seus irmãos 
e, por isso, já estava no Egito, convidou os irmãos a buscarem também seu pai, Jacó, para a terra do rio Nilo ( $\mathrm{Gn}$ 46, 1-7). Essa migração fez com que, finalmente, todos os filhos de Jacó se reunissem no Egito; eram setenta pessoas (Gn 46, 8-27). (GRENZER, 2013, p. 84).

Portanto, o Egito é pensado como terra que acolhe imigrantes necessitados. Nesse sentido, o livro do Êxodo, na parte das tradições jurídicas, novamente lembra seus ouvintesleitores israelitas de que "[...] foram imigrantes na terra do Egito" (Ex 22, 20; 23, 9). E, em vista disso, os hebreus libertados, ao atravessarem o deserto e enfrentarem a escassez de alimentos, correm o risco de “[...] se arrependerem e quererem voltar para o Egito" (Ex 13, 17), achando que "[...] lhes era melhor servir aos egípcios” (Ex 14, 12) do que enfrentar privações e ausência de bem-estar em seu caminho rumo à construção de uma nova sociedade na terra prometida. Enfim, por mais que a memória cultivada em relação à vida no Egito seja ilusória e enganadora, as terras no rio Nilo sempre são lembradas e pensadas como lugar capaz de assegurar a sobrevivência. É terra para onde se migra em momento de miséria. Por isso, vale o seguinte mandamento para Israel: "Não detestarás um egípcio, porque imigrante foste na terra dele!” (Dt 23, 8).

Além disso, ainda nos primeiros dois capítulos do livro do Êxodo, surgem algumas mulheres egípcias com um comportamento salvador em relação a Moisés, o qual é identificado por elas com uma “criança hebreia” (Ex 2, 6). No caso, a filha do faraó, ajudada por suas criadas, “sente compaixão por” Moisés, ao “ver a criança chorar” (Ex 2, 5-6). Mais ainda, "quando a criança [Moisés] ficou grande", "chega a ser um filho para ela" (Ex 2,10). Existe, portanto, no palácio do faraó uma voz mais humana (GRENZER, 2006). Nessa mesma linha de pensamento, "as parteiras das hebreias", "Séfra" e "Fua" (Ex 1, 15), ao "não fazerem o que o rei do Egito lhes fala" (Ex 1, 17), salvam meninos hebreus. E tais parteiras não precisam ser necessariamente hebreias. Talvez sejam mais bem contempladas como ajudantes egípcias das parturientes hebreias, “[...] o que explicaria sua proximidade ao rei egípcio.” (UTZSCHNEIDER; OSWALD, 2013, p. 79). Enfim, no início do livro do Êxodo, surpreendentemente, mulheres egípcias ganham destaque na narração de suas atitudes corajosas em defesa de crianças hebreias.

Outro elemento na narrativa do êxodo que, em princípio, leva o ouvinte-leitor a imaginar uma relação positiva entre o Senhor, Deus de Israel, e o faraó, rei do Egito, aparece nas histórias sobre os sinais e/ou as pragas (Ex 7, 14; 11, 10), assim como na narrativa sobre a saída do Egito (Ex 12, 1-14; 31). Promove-se a ideia de que o Deus dos hebreus, em princípio, se propunha a tornar forte o coração do faraó, no sentido de reforçá-lo e dar-lhe forças (ver o verbo hebraico qzx no grau do piel em Ex 4, 21; 9, 12; 10, 20-27; 11, 10). A 
intenção, aparentemente, era favorecer que o rei do Egito pensasse o que precisava pensar, uma vez que, na antiguidade e na cultura do antigo Israel, o coração representava, sobretudo, o raciocínio. Nesse sentido, era preciso que o faraó compreendesse que não lhe seria possível impedir para sempre a liberdade dos por ele oprimidos. Contudo, o faraó não reagiu como previsto. Pelo contrário, seu coração, reforçado pelo Senhor, Deus de Israel, o levou a, definitivamente, insistir na perseguição, por mais que isso lhe pudesse custar a vida (Ex 14, 4-8). Na linha desse pensamento, compreende-se também outra formulação: o Senhor, Deus de Israel, se propôs a atribuir peso ou importância ao coração do faraó, no sentido de honrá-lo e, portanto, aumentar a autonomia dele (ver o verbo hebraico כבד no grau do hifil em Ex 10, 1). Mais ainda, nem quando o Deus dos hebreus "mostrou dureza" com o coração do faraó (ver o verbo hebraico קשe no grau do hifil em Ex 7, 3) ou "Ihe enviou sinais ao coração" (ver o verbo hebraico שלח no grau do qal com a preposição em Ex 9, 14) ele visou a uma obstinação, a um pesar ou a um endurecimento que não mais deixasse espaço para um entendimento positivo e/ou a conversão do faraó. Quer dizer, acolhendo a reflexão teológica proposta pela narrativa bíblica, o Senhor, Deus de Israel, insiste no livrearbítrio do faraó e na capacidade dele de, como governador responsável, chegar a uma decisão favorável a todos. Por nada, existe uma predestinação ao mal, mas, pelo contrário, um respeito positivo ao Egito e a seu líder (KELLENBERGER, 2006, p. 16-177).

Resumindo, com os pormenores do livro do Êxodo até aqui mencionados, percebe-se que o segundo livro do Pentateuco olha de forma mais ampla e diferenciada para o Egito do que comumente se entende: ora se sabe que as terras no rio Nilo são um destino para muitos que ali se refugiam como imigrantes, ora se enxerga o povo egípcio como sociedade no meio da qual existem vozes bem humanas. Além disso, põe-se fé na possibilidade de o governador do Egito abandonar suas políticas opressivas. Contudo, o livro do Êxodo vai ainda mais além.

\section{LIBERTAÇÃO OU DESPOJAMENTO DOS EGÍPCIOS?}

É possível descobrir que o livro do Êxodo investe na ideia de que, semelhantemente aos hebreus, também os egípcios são libertados. Por duas vezes, tal reflexão vem à tona: quando, na narrativa sobre a vocação de Moisés, um discurso direto atribuído ao Senhor, Deus de Israel, visa, em forma de promessa, ao comportamento das mulheres hebreias e egípcias no momento da saída do povo hebreu do Egito (Ex 3, 21-22); quando se narra o cumprimento dessa promessa (Ex 12, 35-36), sendo que Moisés, antes disso, é novamente solicitado uma segunda vez a insistir na prevista transferência de bens materiais (Ex 11, 1- 
3). Eis uma tradução literal dos três trechos em questão, os quais, originalmente, foram compostos em hebraico:

$3^{21}$ "E infundirei, nos olhos dos egípcios, comiseração por esse povo. Acontecerá que, quando fordes, não ireis sem nada, ${ }^{22}$ mas cada mulher solicitará, de sua vizinha ou da hospedeira de sua família, objetos de prata, objetos de ouro e vestimentas que colocareis sobre vossos filhos e vossas filhas. Libertareis, pois, os egípcios".

$11^{2}$ "Fala, por favor, aos ouvidos do povo, a fim de que homem e mulher solicitem a seu companheiro e sua companheira objetos de prata e objetos de ouro!" 3 E o SENHOR infundiu, nos olhos dos egípcios, comiseração pelo povo.

$12^{35}$ Os filhos de Israel agiram de acordo com a palavra de Moisés e solicitaram dos egípcios objetos de prata, objetos de ouro e vestimentas. ${ }^{36} \mathrm{E}$ o SENHOR infundiu, nos olhos dos egípcios, comiseração pelo povo. Deixaram-nos fazer as solicitações, para que libertassem os egípcios.

O presente estudo se propõe a investigar a raiz verbal aqui traduzida como libertar (נצל). Flexionada nos graus verbais do Nifal, Piel, Hifil, Hofal e Hitpael, o vocábulo em questão aparece, no total, duzentas e treze vezes na Bíblia Hebraica (HOSSFELD; KALTHOFF, 1998, p. 533-540; BERGMANN, 1984, p. 96-99). No livro do Êxodo, por sua vez, são apenas catorze presenças (Ex 2, 19; 3, 8-22; 5, 23²x; 6, 6; 12, 27-36; 18, 4-8.9.10²x; $33,6)$. Em princípio, prevalece em relação à carga semântica sempre a ideia de o verbo indicar uma ação libertadora e, com isso, salvadora. Somente em vista de Ex 3, 22c; 12, 36c ocorre, desde a tradução da Septuaginta nos séculos III a II a.C., algo contrário.

No caso, um olhar para as traduções da Bíblia em língua portuguesa, para os dicionários de hebraico bíblico-português e para os comentários do livro do Êxodo permite ver que, no que se refere à raiz verbal נצל em Ex 3, 22c; 12, 36c, se chega a uma compreensão negativa da carga semântica dela. Em vez de libertarem os egípcios, os hebreus teriam espoliado (BÍBLIA SAGRADA, 2001) e/ou despojado os egípcios (BÍBLIA SAGRADA, 2018; BÍBLIA SAGRADA, 2017; BÍBLIA MENSAGEM DE DEUS, 2016; NOVA BÍBLIA PASTORAL, 2014; BÍBLIA DE JERUSALÉM, 2002; BÍBLIA DO PEREGRINO, 2002; BÍBLIA TRADUÇÃO ECUMÊNICA, 1994). Os Dicionários de Hebraico Bíblico-Português insistem no mesmo tipo de significado para traduzir o verbo נצל, flexionado no grau do Piel: confira as alternativas "saquear, roubar, despojar; tomar, abocanhar, arrebatar (para si); arrancar, salvar" em Kirst et al. (2013, p. 160), "saquear, despojar, espoliar, tomar despojos” em Alonso Schökel (1997, p. 446) ou, especificamente para Ex 3, 22; 12, 36, "pilhar, despojar” em Holladay (2010, p. 346). Também os Comentários ao Livro do Êxodo, embora vejam nisso algo estranho e moralmente reprovável, imaginam que os hebreus tivessem despojado os egípcios (ANDIÑACH, 2010, p. 74-75; 166; PIXLEY, 1987, p. 42; 83). 
No entanto, existem argumentos de maior peso para uma leitura diferente do verbo נצל Ex Ex 3, 22c; 12, 36c. Nesse sentido, antes de tudo, é importante observar que a própria narrativa bíblica nem minimamente alude a uma agressão ou a um conflito violento, sendo que as pessoas mencionadas (Ex 3, 22: mulher, vizinha, hospedeira, filhos e filhas; Ex 11, 2: companheiro ou próximo, companheira ou próxima) “[...] apontam para uma convivência pacífica e benevolente.” (FISCHER, 2011, p. 208). Nessa linha de pensamento, também é preciso levar em conta que os textos bíblicos em questão, por quatro vezes, destacam que, por parte dos hebreus, houve uma solicitação ou um pedido em vista da transferência de alguns bens materiais (Ex 3, 22; 11, 2; 12, 35-36), e não um roubo e/ou um despojamento. Dessa forma, narra-se que "o povo dos israelitas encontrou graça junto aos egípcios", no sentido de ter sido “[...] a obra do Senhor quando, nos egípcios, prevaleceu uma atitude positiva em relação aos israelitas.” (FISCHER, 1989, p. 165). Quer dizer, no que se refere aos israelitas, os egípcios “deixaram-nos fazer a solicitação” (Ex 12, 36), algo que já possibilita uma postura concedente da parte de quem podia atender ao pedido, pois, de acordo com o que é narrado no livro do Êxodo, foi justamente o Senhor, Deus de Israel, quem proporcionou ou "[...] infundiu nos olhos dos egípcios comiseração pelo povo" hebreu $(\mathrm{Ex} 3,21 ; 11,3 ; 12,36)$.

Existem ainda outras observações que tornam improvável a ideia de que o texto hebraico em Ex 3, 22; 12, 36 vise a um despojamento dos egípcios por parte dos hebreus. No caso, não se menciona a quantidade dos bens recebidos pelos israelitas, além de, em Ex 3, 22, ser dito expressamente que os sujeitos atuantes são mulheres - apenas mais tarde, os homens se juntam à dinâmica proposta $(\operatorname{Ex} 11,2 ; 12,35)$ - e que "[...] crianças dos dois gêneros [... são] os recebedores” (FISCHER, 2011, p. 210) dos bens. Portanto, não ocorre uma alusão a jovens ou homens guerreiros ( $\mathrm{Gn}$ 14, 24), o que seria comum no contexto da distribuição de despojos.

Outro detalhe chama a atenção. Das cento e cinco presenças de prata (Ex 3, 22; 11, 2; 12, 35), noventa e sete pertencem às tradições sobre a construção do santuário no deserto (Ex 25-31; 35-40). Exatamente o mesmo vale para o ouro (Ex 3, 22; 11, 2; 12, 35). Além

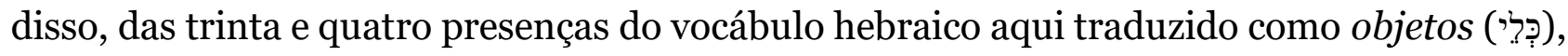
seis se encontram em Ex 3, 22; 11, 2; 12, 35 e vinte e sete nos textos sobre o santuário. As vestimentas ( $\operatorname{Ex} 3,22 ; 12,35)$, por sua vez, mais bem compreendidas como "lençóis" (BENDER, 2008, p. 91-95), ora aparecem para carregar utensílios como as amassadeiras (Ex 12, 34), ora como vestimenta que, após lavada, é usada no momento do encontro com o Senhor, Deus de Israel (Ex 19, 10-14). Portanto, tanto os objetos de prata e ouro como as 
vestimentas não representam despojos que, materialmente, enriquecessem os israelitas, mas, como já observado por Irineu de Lyon (ca. 130-202) ou Orígenes (ca. 185-252), seu “[...] uso correto se encontra em sua destinação ao serviço a Deus” (HEITHER, 2002, p. 7374).

Outro pormenor merece atenção ainda. Onde se traduziu aqui, por seis vezes, o gentílico os egípcios ( $\operatorname{Ex} 3,21-22 ; 11,3 ; 12,35-36^{2 x}$ ), a vocalização dos massoretas leva o ouvinte-leitor a compreender o Egito. Como já dito acima, o texto não vocalizado permite as duas compreensões. Nesse sentido, é mais fácil pensar nos olhos dos egípcios (Ex 3, 21; 11, $3 ; 12,36)$ do que nos olhos do Egito. No entanto, mesmo assim, é importante perceber que o texto bíblico, sobretudo, visa ao Egito como um poder com conotações simbólicas, no sentido de essa nação representar um poder opressivo, sendo que "[...] a intervenção divina não se dirige contra os seres humanos, mas à anulação de condições ilegais e indignas à pessoa humana." (FISCHER, 2011, p. 209).

Enfim, o conjunto das observações apresentadas até aqui torna provável a seguinte compreensão de Ex 3, 22; 12, 36: em vez de imaginar um despojamento dos egípcios por parte dos hebreus, mesmo no sentido de que estes últimos fizessem valer seu direito de não saírem da servidão sem nada (Ex 3, 21; Dt 15, 13-14), os textos hebraicos em questão visam, na realidade, à libertação dos egípcios e/ou do Egito. Quer dizer, “[...] a tão comum interpretação pejorativa do verbo נצל no grau do Piel, no sentido de despojar ou roubar, não faz justiça ao texto bíblico." (UTZSCHNEIDER; OSWALD, 2013, p. 132). Pelo contrário, de acordo com todos os paralelismos referentes a este verbo hebraico, indica-se, também para as duas ocorrências em Ex 3, 22; 12, 36, a carga semântica de libertar, no sentido de imaginar-se uma dinâmica salvadora para o povo egípcio.

Em outras palavras, os hebreus “[...] vão embora de forma harmônica” e na base de um "bom entendimento" (FISCHER; MARKL, 2009, p. 61-62). Assim como José já podia experimentar o comportamento bondoso de um egípcio, justamente quando "[...] o SENHOR lhe estendia sua lealdade ao infundir sua comiseração nos olhos do chefe da prisão" (Gn 39, 21), também os hebreus são convidados a experimentar "[...] a comiseração dos egípcios por seu povo.” (Ex 3, 21; 11, 3; 12, 36). Assim, “[...] os egípcios participam de alguma forma da salvação dos israelitas [...]”, sendo que tal salvação parte novamente da “[...] colaboração entre mulheres hebreias e egípcias como no contexto do nascimento e da salvação de Moisés (Ex 2, 1-10).” (DOHMEN, 2015, p. 168).

Percebe-se, portanto, que a transferência de bens aos oprimidos e a libertação deles podem se tornar também uma realidade libertadora para quem, em princípio, se encontra 
favorecido pelo poder opressivo, lembrando-se de que um favorecimento desse tipo, como amplamente exposto pelas narrativas sobre as pragas (Ex 7-12), somente seria uma ilusão dolorida. Nesse sentido, por mais que isso teologicamente seja uma ideia desafiante, é preferível descobrir que "[...] o êxodo dos israelitas significa também a libertação dos egípcios" (FISCHER, 2011, p. 213).

\section{CONSIDERAÇÕES FINAIS}

Teologias políticas sempre são complexas. De um lado, pois, elas se propõem a refletir sobre sociedades, povos e nações. Assim descobrem que, dificilmente, existem realidades uniformes. Os seres humanos não pensam de forma igual, sendo que, por causa disso, existem compreensões diferentes da realidade e, consequentemente, comportamentos e políticas que se opõem. Isso vale também para aquelas nações que, em vista de interesses próprios, usam seu poder para promover políticas opressivas. De outro lado, as teologias políticas se propõem a levar a questão de Deus em consideração. Também em vista disso, de longe não existe unanimidade entre os estudiosos, mesmo que, no caso de teologias judaicas e cristãs, os textos bíblicos sejam consultados por todos como fonte primeira; porém, como visto acima, a compreensão de tais textos ainda depende de análises exegéticas mais exatas. No caso, a tradução errada e, com isso, o entendimento equivocado de uma só palavra podem provocar a má compreensão de narrativas e, com isso, de obras literárias inteiras.

Contudo, na base do que foi estudado aqui sobre Ex 3, 33; 12, 36, afirma-se que a teologia política promovida pelo livro do Êxodo propõe um raciocínio que, com base na reflexão sobre o Senhor, Deus de Israel, imagina a salvação de todos a partir de uma postura solidária com os mais necessitados. Nesse sentido, os textos bíblicos em questão indicam a participação ativa de quem tem condições para isso no processo de libertação dos miseráveis, prevendo-se a inversão total do destino destes últimos, ou seja, a saída física deles da sociedade que os oprime, um longo processo de instrução e aprendizagem e a construção de uma sociedade alternativa, mais justa e igualitária em terras novas. Isso, por sua vez, inclui também a transferência de bens materiais a quem deve enfrentar o caminho rumo à liberdade.

Mais ainda, além de essa transferência de bens ser algo justo, as tradições exodais imaginam tal partilha não como uma perda para quem divide seu patrimônio com os necessitados, mas sim como libertação. O resultado desse processo, pois, poderá ser a 
superação de conflitos graves e, além disso, a experiência surpreendente de convivências novas, pacíficas e livres de violências mortais.

\section{REFERÊNCIAS}

ALONSO SCHÖKEL, L. Dicionário Bíblico Hebraico-Português. São Paulo: Paulus, 1997.

ANDIÑACH, P. R. O Livro do Êxodo: um comentário exegético-teológico. São Leopoldo: Sinodal, 2010.

BENDER, C. Die Sprache der Textilien: Untersuchungen zu Kleidung und Textilien im Alten Testament. Stuttgart: Kohlhammer, 2008.

BERGMANN, U. נצל nșl hi. retten. In: JENNI, E.; WESTERMANN, C. (eds.).

Theologisches Handwörterbuch zum Alten Testament. v. II. München: Kaiser; Zürich: Theologischer Verlag: 1984, p. 96-99.

BÍBLIA DE JERUSALÉM: nova edição, revista e ampliada. São Paulo: Paulus, 2002.

BÍBLIA DO PEREGRINO. São Paulo: Paulus, 2002.

BÍBLIA MENSAGEM DE DEUS. 3. ed. São Paulo: Loyola, 2016.

BÍBLIA SAGRADA. 45. ed. Petrópolis: Vozes, 2001.

BÍBLIA SAGRADA: letra gigante. Traduzida por João Ferreira de Almeida. Revista e Atualizada no Brasil. Barueri: Sociedade Bíblica, 2017.

BÍBLIA SAGRADA: tradução oficial da CNBB. Brasília: Edições CNBB, 2018.

BÍBLIA TRADUÇÃO ECUMÊNICA. São Paulo: Loyola, 1994.

DOHMEN, C. Exodus 1-18. Freiburg: Herder, 2015.

ELLIGER, K.; RUDOLPH, W. (eds.). Biblia Hebraica Stuttgartensia. 4. ed. Stuttgart: Deutsche Bibelgesellschaft, 1997.

FISCHER, G. Jahwe, unser Gott: Sprache, Aufbau und Erzähltechnik in der Berufung des Mose (Ex 3-4). Freiburg, Suiça: Universitätsverlag; Göttingen: Vandenhoeck \& Ruprecht, 1989.

FISCHER, G. Wann begannen die Israeliten, die Ägypter auszuplündern? Zur Interpretationsgeschichte von Ex 3,22 und 12,36. In: FISCHER, G. Die Anfänge der Bibel: Studien zu Genesis und Exodus. Stuttgart: Katholisches Bibelwerk, 2011, p. 203214 .

FISCHER, G.; MARKL, D. Das Buch Exodus. Stuttgart: Katholisches Bibelwerk, 2009. 
GRENZER, M. Do clã de Jacó ao povo de Israel (Ex 1,1-7). Revista de Cultura

Teológica, São Paulo, v. 21, n. 81, p. 83-94, 2013.

GRENZER, M. Em defesa da criança (Ex 1,15-2,10). Revista de Cultura Teológica, São Paulo, v. 14, n. 55, p. 25-37, 2006.

HEITHER, T. Schriftauslegung: das Buch Exodus bei den Kirchenvätern. Stuttgart:

Katholisches Bibelwerk, 2002.

HOLLADAY, W. L. Léxico Hebraico e Aramaico do Antigo Testamento. São Paulo: Vida Nova, 2010.

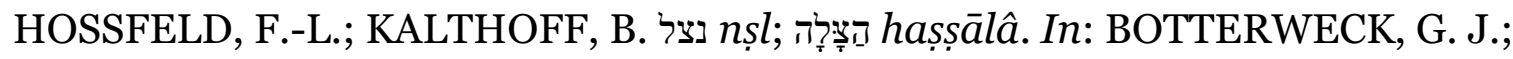

RINGGREN, H.; FABRY, H.-J. (eds.). Theological Dictionary of the Old Testament. v. IX. Grand Rapids, Michigan; Cambridge: Eerdmans, 1998, p. 533-540.

KELLENBERGER, E. Die Verstockung Pharaos: exegetische und auslegungsgeschichtliche Untersuchungen zu Exodus 1-15. Stuttgart: Kohlhammer, 2006.

KESSLER, R. Die Ägyptenbilder der Hebräischen Bibel: Ein Beitrag zur neueren Monotheismusdebatte. Stuttgart: Katholisches Bibelwerk, 2002.

KIRST, N. et al. Dicionário Hebraico-Português e Aramaico-Português. 27. ed. São Leopoldo: Sinodal; Petrópolis: Vozes, 2013.

NOVA BÍBLIA PASTORAL. São Paulo: Paulus, 2014.

PIXLEY, J. Êxodo. São Paulo: Paulus, 1987.

UTZSCHNEIDER, H.; OSWALD, W. Exodus 1-15. Stuttgart: Kohlhammer, 2013. 